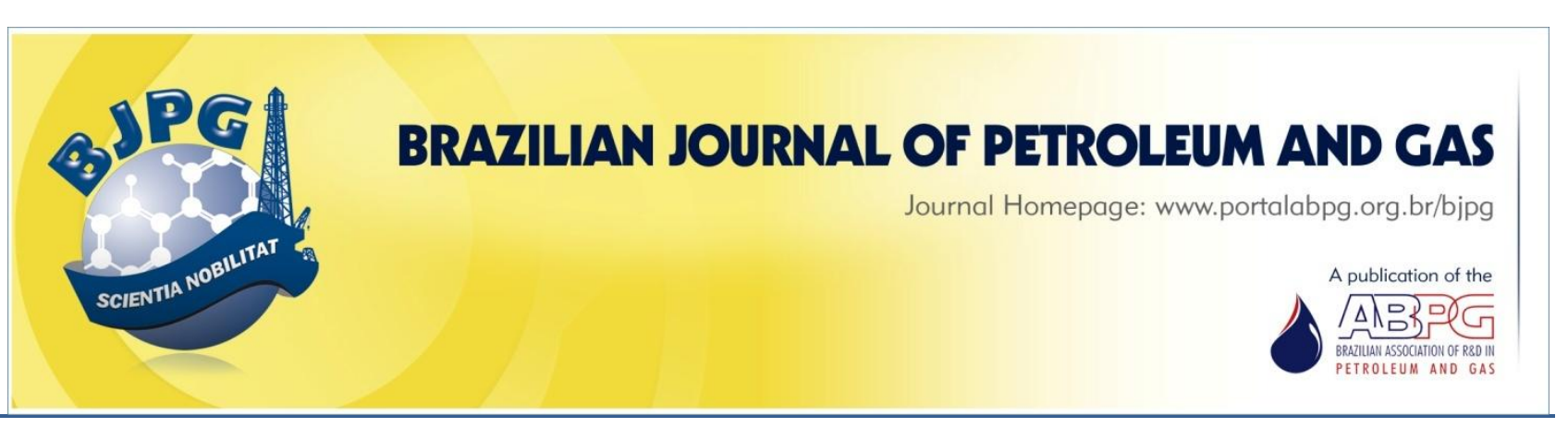

\title{
DEVELOPMENT OF A GUI INTERFACE FOR GEOPRESSURE DETECTION DURING WELL DRILLING
}

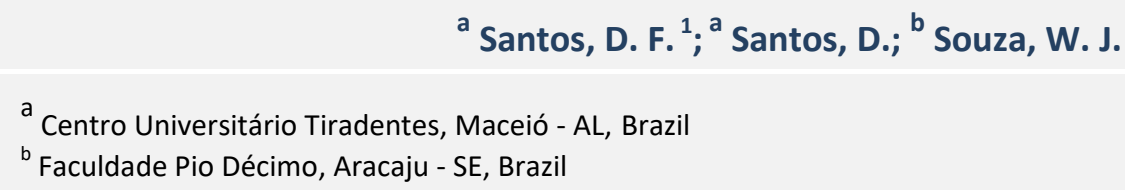

Received: 07.12.2017 / Revised: 15.02.2018 / Accepted: 16.02.2018 / Published on line: 16.04.2018

\begin{abstract}
Geopressure studies are one of the most important activities in the upstream sector of oil industry. The geological formation analysis of the existing prospectus of a sedimentary basin enables the measurement of overload, fracture, and pore pressures. Geopressure can be understood as any pressure or stress on a geological formation, whether on macro or microscopic scale. The estimate of geopressure is one of the most important steps for the establishment of an engineering design of drilling operations and well design. The aim of this work is to present the development of a GUI developed for geopressure analysis, i.e. pore pressure curves, fracture curves, and collapse curves. This work presents the definition of geopressure and GUI interface development protocols for a petroleum engineer, as well as real examples and windows of absorption tests with the appropriate operating depths where they are seated shoes.
\end{abstract}

\section{KEYWORDS}

Matlab GUI; well drilling; geopressured

\footnotetext{
${ }^{1}$ To whom all correspondence should be addressed.

Address: Centro Universitário Tiradentes, Av. Comendador Gustavo Paiva, 5017 - Cruz das Almas, Maceió - AL, Brasil. ZIP Code: 57038-00| e-mail: dheiver.francisco@souunit.com.br ORCID: https://orcid.org/0000-0002-8599-9436 doi:10.5419/bjpg2018-0005
} 


\section{INTRODUCTION}

An oil well is drilled in stages, each stage being determined by the drill diameter or reamer being used in the drilling. The number of phases depends on the characteristics of perforated zones and the well's final depth. There are usually three to four phases, but this number can get to eight in some cases. These phases are completed with the descent of a column of coating and cementing. The reasons for drilling in stages and, consequently, the need for coating may vary but, in general, they are associated with pressures and tensions in the basement, and all those that are imposed on training which can even lead to rock failure. These pressures are called geopressures. Geopressures properties allow the casing shoe depth determination, in which its lower limit is determined by the gradient pores curve, and its upper limit corresponds to the fracture gradient (Lyons et al., 2015).

The balance of pressure between reservoir rock and well is a very important variable related to well drilling. If the pressure in the well is greater than the pressure in the reservoir pores, the circulating fluid penetrates the porous formation. If the formation is permeable and the pressure in the well is lower than the pressure in the reservoir pores, invasion will occur towards the end. During the well drilling, there are disorders that cause fluctuations in pressure. For instance, the increased pressure observed with increased well length. Reservoir parameters such as permeability and pore pressure affect the influx of reservoir fluids into the well, altering the density and fluid mixture flow rate and, consequently, changing the system's pressure. A conventional drilling technique is to maintain the pressure in the well higher than the pressure in the reservoir pores, preventing the occurrence of kicks and blowouts (controllable and uncontrollable influxes of native fluids from the reservoir towards the pit, respectively). However, the fluid will have the tendency to invade the reservoir rock, which can cause irreversible damage to it, reducing its original permeability and affecting the oil well production (Ai et al., 2012; Handal, 2013; Rohani, 2012; Vega et al., 2012).

The literature reports work with manual control (Jenner et al., 2005; Perez-Tellez et al., 2004) and automatic control strategies, motivated by the existence of wells with windows for operating pore pressures and fracture pressure, which makes it smaller (Nygaard et al., 2004ab).

The well control aided by a graphical interface for the area of drilling allows the user interaction with a computer program through graphical elements (buttons, menus, and others), i.e. bring ease to the operator to view variables such as permeability, pore pressure, influx of reservoir fluids into the well, density, and fluid mixture flow rate. The environment GUIDE allows the manual creation of a graphical user interface (GUIGraphical User Interface) quick and easy. The GUIDE development respects the event-oriented programming. In this programming type, unlike traditional programs that follow a standardized flow of control, the flow control of event-oriented programs are guided by external indications, called events. Graphical interfaces can also be created in MATLAB with just simple code programming (programmatic creation).

The geopressures studies represent one essential parameter to the typical design of a pit, where its proper evaluation minimizes possible operational problems during the drilling process. The geopressures quantification is made by gradients estimation of overload, pores, and fractures. The purpose of this study is to develop a GUI interface for monitoring the various known pressures during the process of well drilling. This work can assist in understanding the actual behavior of a drilling process. It was used for the construction of GUI programming in high level, developed in the MATLAB platform.

\section{THEORY SECTION}

\subsection{Pressure gradient}

By definition, pressure gradient is the ratio between pressure and depth, usually referenced to the rotary probe table. However, it is very common that the pressure gradients are expressed in units of density, as in $\mathrm{lb} / \mathrm{gal}$ or $\mathrm{g} . \mathrm{cm}^{-3}$, for a direct comparison with the drilling fluid density (Hossain \& Al-Majed, 2015).

\subsection{Pore pressure}

The pore pressure, also known as the formation pressure, is the pressure where the fluids are 
contained in the pores of a particular formation. The pore gradient is understood as the ratio of its pressure by the depth in which it is active. The formation pressure (also called static pressure) is defined as the fluid pressure contained in the rocks porous spaces. For the pore pressure estimation, the literature uses direct methods that hold it in permeable formations, and indirect methods that work in formations with very low permeability. The pore pressure is very important to set the drilling rig being used, since the drilling fluid is responsible for controlling the pressure inside the well, stopping the flow inside the interior, and ensuring well stability. In impermeable formations, as shales cannot measure the pore pressure directly, pore pressure can be estimated using indirect methods, which are based on the interpretation of parameters, i.e. electrical profiles (Hossain \& AlMajed, 2015).

\subsection{Collapse pressure}

Collapse pressure is the pressure that leads to the breakdown of the rock by shear under compression stress. The rupture by collapse can occur either due to a low weight of the drilling fluid or due to excessive fluid weight. The disruptions of consequences in operational terms will vary according to the type of rock. A typical case is when failures of rock by shear cause deformation in diameter, increasing the torque in drilling column, leading to its imprisonment. In other types of training, the failure by shear can lead to partial or total collapse, with possible column imprisonment due to collapsed gravels (Hossain \& Al-Majed, 2015).

\subsection{Fracture pressure}

The fracture pressure is the pressure that leads to failure of rock by traction. The fracture may occur the same way that it does in the formation collapse - by reference to the use of a low weight of drilling fluid, as well as on the basis of the use of a high weight drilling fluid. When put into practice, the occurrence of a higher fracture is more common than a lower fracture. The operational consequences of a failure by fracture are landslides or loss of drilling fluid to the training, known as loss of circulation, respectively. The fracture gradient estimation can be made utilizing direct measurements or using calculation techniques based on theoretical or empirical models (indirect methods). The direct fracture pressure measurement is usually done through tests that identify if the drilling fluid is pressurized in a controlled way into the well. Choosing the test type will depend on the scenario in which the well is located and, on the information, requested such as absorption, pressure of breaks, or the minimum voltage. The direct methods provide very reliable values, sometimes at a high cost. The values that these tests provide are punctual and often carried out in specific formations like shale. Companies that perform these measurements keep the data in a database to be used in punctual calibration of fracture gradient curves generated by indirect methods (Hossain \& Al-Majed, 2015).

\subsection{Overload pressure}

Overload pressure is the pressure exerted by a certain depth total weight of overlapping layers. The overload pressure at a given depth is a layer's density overlying function (including rock and fluids). Once that pressure does not concern only the fluids and acts on rock matrix, the voltage overload term is also used. In ground pressure overload wells will also have a participation of an excerpt (from the rotary table to the ground), while in the pits, both the excerpt (from rotary table to sea level) as the blade of water are considered. The air presents a value close to zero and is usually neglected in the calculations. The overload gradient determination is of vital importance for estimating geopressures curves, so the more check your determination, the more accurate the results obtained from pore, fracture, and collapse pressures will be. The pressure overload is defined in terms of three parameters: specific mass, gravity acceleration and the depth. The gravity acceleration will be known due to as the well depth. The specific mass will be the only unknown parameter to determine the pressure overload. To determine the specific mass of formations one can use mathematic correlations or experimental measurements (Hossain \& Al-Majed, 2015).

\subsection{Operational window}

The operational window is an item indispensable in a well design. It is also the main parameter to be used to evaluate the stability of a well during piercing. Obtaining the operating window, which has the allowable range for the variation of density and consequently the mud 
weight, will provide a stable and safe drilling environment limiting possible problems. Usually, the operating window lower bound is represented by the largest pore pressure gradient value and collapse gradient. The upper limit is represented by the fracture gradient curve. The fluid density must be conditioned to promote a hydrostatic pressure to meet each stage in this range, not exceeding any mentioned limits, so that the drilling stabilization occurs. The operational window sets the nesting depth of shoes, because it shows the excerpts in which a certain weight of fluid is compatible, defining the depths of coatings and setting out the stages of well drilling. Making the choice of coatings and the shoe position one is ready to make well cementing wall. Pressure curves are obtained with tensions. Pressures present in the subsoil and imposed on the formations can lead to rock failure. These pressures are: overload pressure, pore pressure, collapse pressure and fracture pressure (Hossain \& Al-Majed, 2015).

To determine the depths where deeper jackets shoes must be settled, one can use a criterion based only on operational window as well as a criterion based on tolerance to kick. Using the settlement criteria based only the operational window, it is possible to define the seating depth directly using the bounds of the operating window. One can also use safety margins which vary from company to company. This criterion should be used to define the seating depths, that is, the well's final depth known plot a line vertical in operating window to cross the upper boundary, where one should find the flooring shoe. From that point, one can set the depth of the other shoes doing the same procedure, tracing the vertical arrow from the last shoe depth. The criterion of settlement based on tolerance to kick, usually gives the ability to close the well safely. Kick tolerance is defined as the maximum pressure of pores that by taking a kick still allows the closing of the pit safely. In this context, security means a way of preventing fracture in any formation of the open pit. The tolerance the kick depends on the influx magnitude, which must be set. The settlement of shoes based on the criterion of tolerance to the "kick" takes into consideration a safety called as margin pores pressure. There are two ways to determine the depth of a nesting shoe based on tolerance to kick: from top to bottom and from bottom to top (Hossain \& Al-Majed, 2015).

\section{MATERIALS AND METHODS}

In MATLAB, there are two ways to develop a GUI: through the GUIDE (the term comes from Graphical User Interface Development

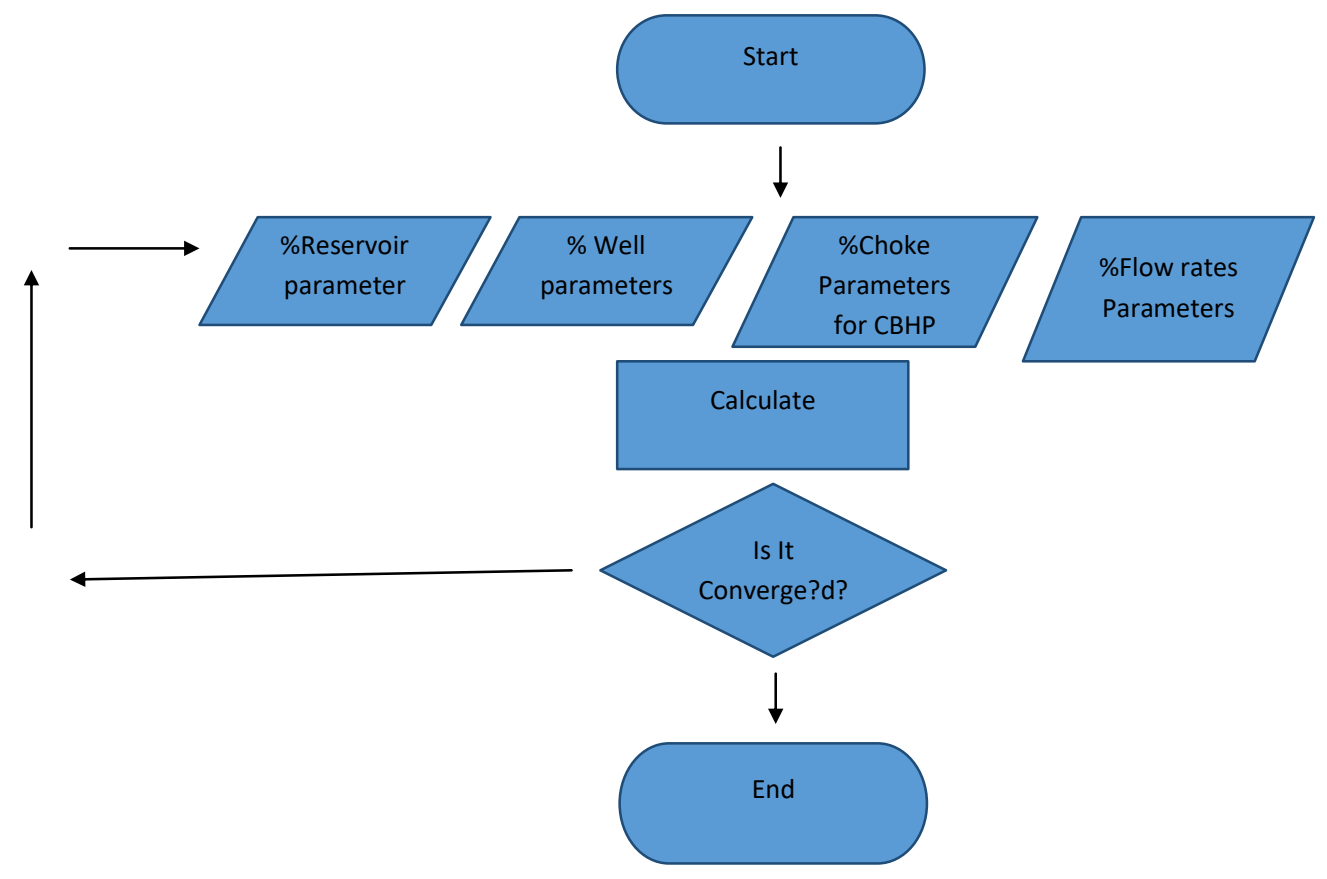

Figure 1. The GUI flow diagram. 
Environment, i.e. an environment focused on developing GUls, providing tools for creation of graphics) and through programming directly in a script. Develop a GUI for programming implies describing all components, their properties and behavior through lines of code. When using the GUIDE, information about the graphic layout is stored in a file extension Fig. Associated with this file there is an " $\mathrm{m}$ " extension, containing lines of code to determine the behavior of each component chart of GUI and its interactions with the user. Because the GUIDE presents greater simplicity in the graphic layout development, it was the method chosen to create the GUI proposal in this work. Following are the basic steps to the platform development.

In this software package, some input fields have to be given on user template, as shown in Figure 1. Screen shots of the GUI are shown in Figure 2.

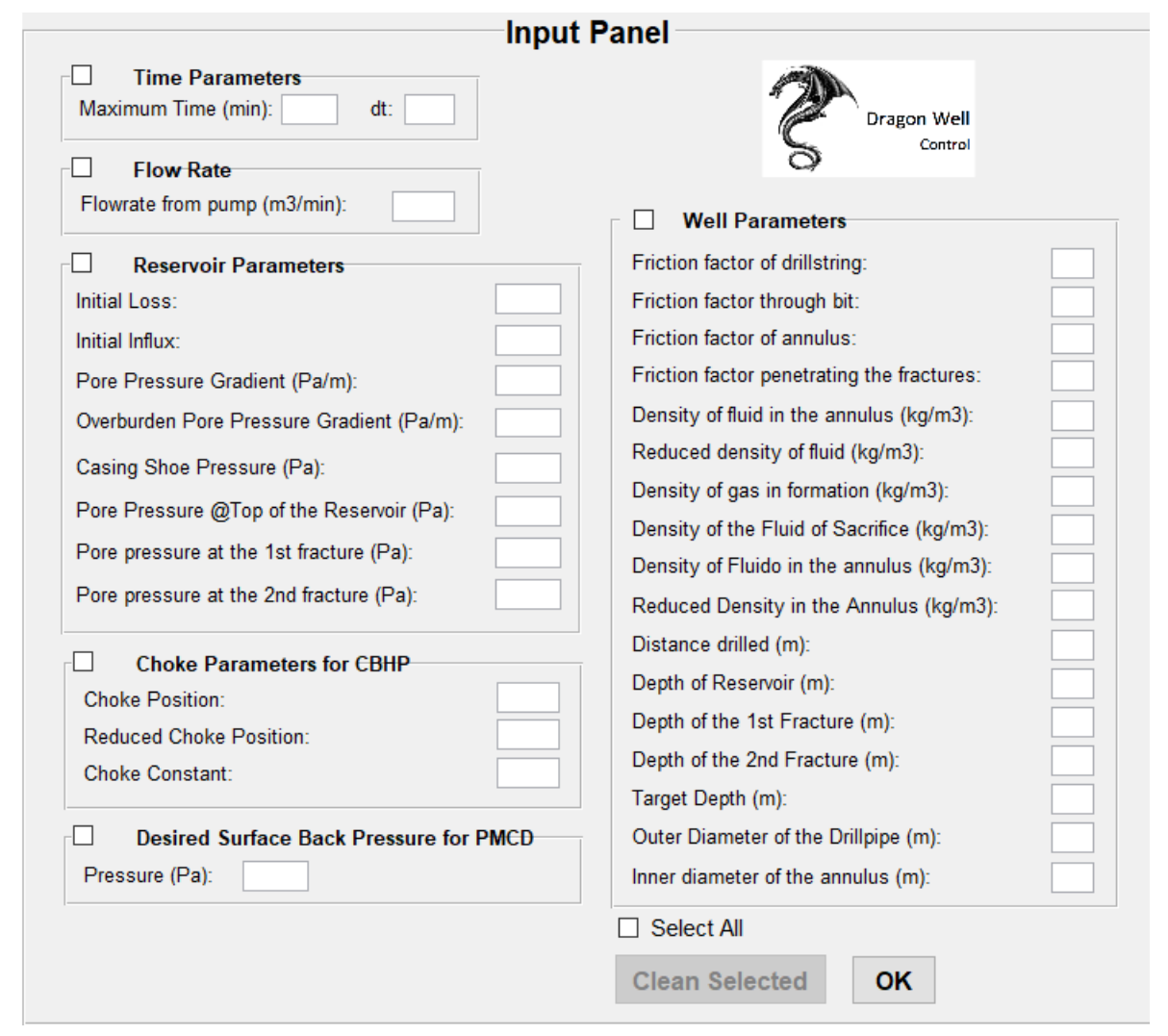

Figure 2. Initial state of GUI.

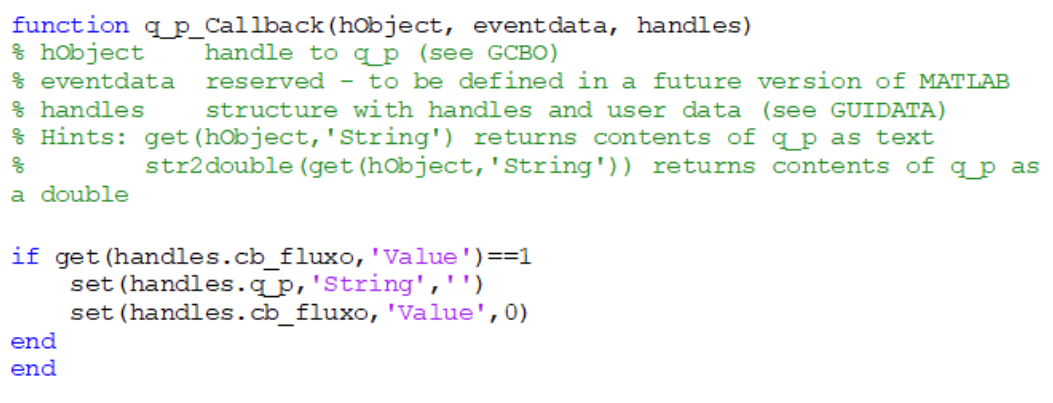

Figure 3. Callback function at the matlab. 

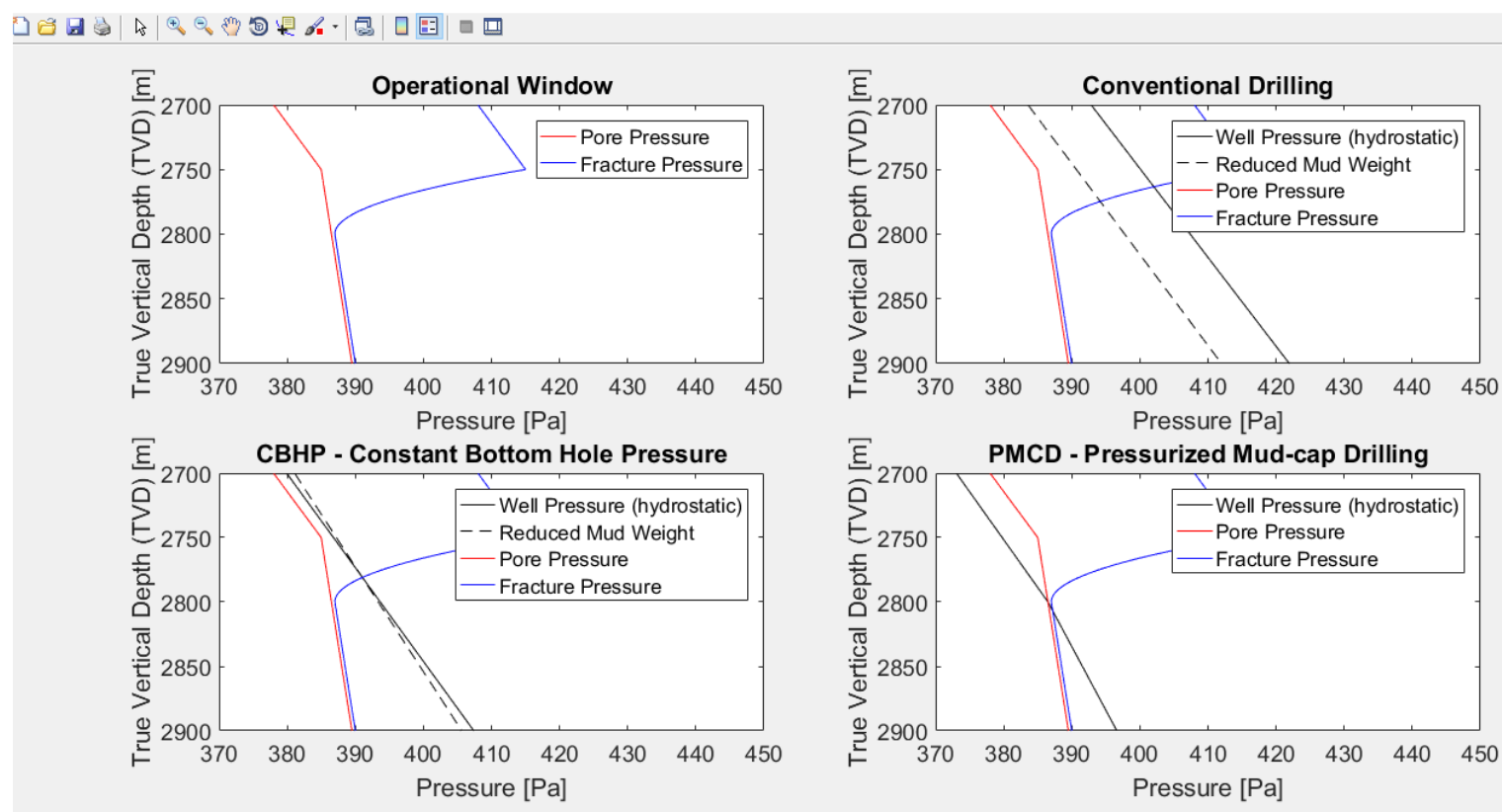

Figure 4. Output of software.

The lector wondered how the authors linked a particular event created in GUI interface (text box and a given numeric value) for a particular function. To associate events to problem variables, one can use the so-called callbacks. This term works as follows: a menu will appear when one click the right button on the variable created in the GUI This menu presents the option "view Callbacks" that showed all available callbacks for a component (Figure 3).

\section{RESULTS AND DISCUSSION}

Figure 4 presents the various geopressures, which can be understood as any pressure or stress on a geological formation, whether in macro or microscopic scale. The goal of geopressures is to determine overload curves, pore pressure, fracture, and collapse pressure. With curves, you can limit the operating window that will define the drilling fluid specific weight and the settlement's shoe. The drilling fluid weight will be bounded at the diagram on the superior part by the overload and voltage gradient curve of fracture, since excess weight can generate traction voltages in the rock and cause cracks with the consequent loss of drilling fluid. The drilling fluid weight will be bounded at the diagram on the inferior part by the lower collapse pressure curve and the pore pressure curve. The settlement's shoe can be positioned with success.

\section{CONCLUSIONS}

The analysis of geopressures is crucial for the design of a well, due to possible operational problems related to its inappropriate estimate. Some of these problems may result in additional costs for drilling as well as loss of production time. This work presents the types of geopressure that make up the operating window. This information is of great importance in the design of wells because it determines the variation allowed for the pressure exerted by the drilling fluid inside the well, to maintain the drilling in safe conditions, respecting the well limitations. It was also presents ways to determine the depth of coating shoes. A GUI for the area of drilling is a very useful tool for students, engineers, and scientists. The work was developed using MATLAB ${ }^{\circledR}$. A GUI for drilling needs to be visually appealing and easy to use, represent an open source and have a wide range of applicabilities. The programmer must always keep in mind the needs of the users when developing a GUI. 


\section{ACKNOWLEDGEMENTS}

The authors wish to thank Tiradentes University Center (UNIT) for the support provided.

\section{SUPPORTING INFORMATION}

\%Clearing and closing previous variables and plots clear all

close all

\%Time parameter

maxtime=10000; \%Maximum time $(\mathrm{min})$

$\mathrm{dt}=\mathbf{0 . 0 0 1}$

\%Array initialization

BHP_ann_conv_ar=zeros(maxtime,1);

BHP_ann_CBHP_ar=zeros(maxtime,1);

BHP_ann_PMCD_ar=zeros(maxtime,1);

p_pore_ar=zeros(maxtime,1);

p_frac_ar=zeros(maxtime,1);

depth_ar=zeros(maxtime,1);

BHP_ann_convreduced_ar=zeros(maxtime,1);

BHP_ann_CBHPreduced_ar=zeros(maxtime,1);

\%Flow rates

q_p = 2; \% Flowrate from Pump ( $\left.\mathrm{m}^{\wedge} 3 / \mathrm{min}\right)$

q_b=q_p; \% Flowrate through Bit $\mathrm{m}^{\wedge} 3 / \mathrm{min}$ )

\%Reservoir parameter

q_loss=0; \% Initially no losses to the formation

q_res=0; \% Initially no influx from the formation

p_poregrad_res $=0.03 e 5 ; \%$ Pore pressure gradient of the reservoir $(\mathrm{Pa} / \mathrm{m})$

p_poregrad $=0.14 \mathrm{e} 5 ; \%$ Pore pressure gradient of the overburden $(\mathrm{Pa} / \mathrm{m})$

p_pore_csg=378e5; \% Pore pressure at the

previous set csg shoe $(\mathrm{Pa})$

p_pore_topres $=385 \mathrm{e} 5$; $\%$ Pore pressure at the top

of the reservoir $(\mathrm{Pa})$

p_pore_1stfrac=386.5e5; \% Pore pressure at the

1st fracture $(\mathrm{Pa})$

p_pore_2ndfrac $=\mathbf{3 8 8 e 5}$; \% Pore pressure at the

2nd fracture $(\mathrm{Pa})$

$\%$ Well parameters

$\mathrm{Fd}=1 \mathrm{e} 5$; \% Friction factor of drillstring

$\mathrm{Fb}=5 \mathrm{e} 4 ; \%$ Friction factor through bit

$\mathrm{Fa}=2 \mathrm{e} 5 ; \%$ Friction factor of annulus

$\mathrm{Ff}=1 \mathrm{e} 5$; \% Friction factor penetrating the fractures rho_m = 1455; \% Density of fluid in the annulus $\left(\mathrm{kg} / \mathrm{m}^{\wedge} 3\right)$

rho_m_reduced $=1420$; \% Reduced density of fluid in the annulus $\left(\mathrm{kg} / \mathrm{m}^{\wedge} 3\right)$

rho_gas=204; \% Density of gas in formation

$\left(\mathrm{kg} / \mathrm{m}^{\wedge} 3\right)$

rho_sac=1030; \% Density of gas in formation

$\left(\mathrm{kg} / \mathrm{m}^{\wedge} 3\right)$

rho_CBHP=1400; \% Density of fluid in the annulus

$\left(\mathrm{kg} / \mathrm{m}^{\wedge} 3\right)$

rho_CBHP_reduced $=1250 ; \%$ Reduced density of

fluid in the annulus $\left(\mathrm{kg} / \mathrm{m}^{\wedge} 3\right)$

$\mathrm{g}=9.81 ; \%$ Gravity constant $\left(\mathrm{kgm} / \mathrm{s}^{\wedge} 2\right)$

h_csg=2700; \% Distance drilled $(\mathrm{m})$

h_topres $=2750$; \% Depth of reservoir $(\mathrm{m})$

$\mathrm{h} \_1 \mathrm{stfrac}=2800$; \% Depth of 1st fracture $(\mathrm{m})$

h_2ndfrac $=2850$; \% Depth of 2nd fracture $(\mathrm{m})$

h_TD=2900; \% Depth of Target Depth $(\mathrm{m})$

$\mathrm{OD}=\mathbf{0 . 1} ; \%$ Outer diameter of the drillpipe $(\mathrm{m})$

$I D=\mathbf{0 . 2} ; \%$ Inner diameter of the annulus $(\mathrm{m})$

\%Choke Parameters for CBHP

z_c=0.6; \% Choke Position

z_c_reduced $=0.092$; \% Reduced choke position

k_c $=0.375 ; \%$ Choke Constant

\%Desired Surface_back Pressure for PMCD

SBP_desired=10e5;

$\%$ Initial Values

h_drilled=h_csg;

\section{REFERENCES}

Adachi, J. I.; Nagy, Z. R.; Sayers, C. M.; Smith, M. F.; Becker, D. F. Drilling adjacent to salt bodies: Definition of mud weight window and pore pressure using numerical models and fast well planning tool. In: SPE Annual Technical Conference and Exhibition, San Antonio, Texas, USA, p. 1-11, 2012. https://doi.org/10.2118/159739-MS

Handal, A. Safety Barrier Analysis and hazard identification of blowout using managed pressure drilling compared with conventional drilling. In: IADC/SPE Managed Pressure Drilling and Underbalanced Operations Conference and Exhibition, San Antonio, Texas, USA, SPE-164564MS, p. 1-19, 2013. https://doi.org/10.2118/164564$\underline{\mathrm{MS}}$ 
Hossain, M. E.; Al-Majed, A. A. Fundamentals of Sustainable Drilling Engineering. New Jersey: John Wiley \& Sons, Inc. and Scrivener Publishing LLC, ISBN 978-0-470-87817-0, 755p, 2015. https://doi.org/10.1002/9781119100300

Jenner, J. W.; Elkins, H.; Springett, F.; Lurie, P.; Wellings, J. S. The continuous circulation system: An advance in constant pressure drilling. SPE Drilling \& Completion, v. 20, n. 3, p. 11, 2005. https://doi.org/10.2118/90702-PA

Lyons, W. C.; Plisga, G. J.; Lorenz, M. D. Standard Handbook of Petroleum and Natural Gas Engineering. Oxford: Gulf Professional Publishing, $3^{\text {rd }}$ Edition, ISBN 978-0-12-383846-9, 1822p, 2015.

Nygaard, G. H.; Vefring, E. H.; Mylvaganam, S.; Lorentzen, R. J.; Nævdal, G.; Fjelde, K. K. Underbalanced drilling: improving pipe connection procedures using automatic control. In: SPE Annual Technical Conference and Exhibition, SPE 90962, p. 1-17, Houston, TX, USA, 2004a. https://doi.org/10.2118/90962-MS
Nygaard, G. H.; Vefring, E. H.; Fjelde, K. K.; Nævdal, G.; Lorentzen, R. J.; Mylvaganam, S. Bottomhole pressure control during drilling operations in gas-dominant wells. In: SPE/IADC Underbalanced Technology Conference and Exhibition, SPE/IADC 91578, Houston, TX, USA, p. 1-8, 2004b. https://doi.org/10.2118/91578-MS

Perez-Tellez, C.; Smith, J. R.; Edwards, J. K. Improved bottomhole pressure control for underbalanced drilling operations. In: IADC/SPE Drilling Conference, IADC/SPE 87255, Dallas, TX, USA, p. 1-11, 2004. https://doi.org/10.2118/87225-MS

Rohani, M. R. Managed-pressure drilling: Techniques and options for improving operational safety and efficiency. Petroleum and Coal, v. 54, n. 1, p. 24-33, 2012.

Vega, M. P.; Freitas, M. G.; Araujo, N.F.; Scheid, C. M.; Martins, A. L. Oil well drilling inside operational window - Simulation and experimental control studies. Computer Aided Chemical Engineering, v. 30, p. 837-841, 2012. https://doi.org/10.1016/B978-0-444-59520-1.50026-9 